\title{
Analysis of Citizens' Opinions and Practices toward Individual Roles and Responsibilities in Environmental Protection
}

\author{
Neerja Jaiswal and Nisha Arya \\ Department of Family and Community Resource Management, Faculty of Family and Community \\ Sciences, The Maharaja Sayajirao University of Baroda, Vadodara, Gujarat, India \\ Corresponding author email: nancyarya24s@gmail.com
}

\section{ABSTRACT}

The most serious issue of the present day is environmental degradation because of pollution, huge waste generation, unsafe environmental acts, fossil fuel deforestation and changing climate. Through this research, an attempt has been made to assess citizen's opinion in order to determine individual roles and responsibilities, to evaluate the citizen's individual practices oriented toward environmental protection and sustainable development and to study the factors behind the unhealthy behaviour of human towards environment and sustainable development. The present study was descriptive in nature. Random sampling was used to collect data from 165 respondents by using questionnaire method distributed online via, Google form link. The results showed that respondents (73.80\%) were in the age group of 19-35 years were male (54.70\%) and were qualified till (45.60\%). It was reported that respondents (72.70\%) considered 'we' human were extremely behind the environment degradation and assumed that individual's insignificant actions have a significant impact on the environment and sustainable development at high extent (74.50\%). Respondents (42.20\%) were agreed that resources must be properly used. Respondents (80.80\%) flip the light switch off when they leave the rooms either in home or offices most of the times and keep their surrounding clean and hygienic most of the times (70.20\%). It was identified that ignorance (48.40\%) and laziness (45.30\%) among the citizens were the key factors behind the unhealthy behaviour of citizens towards environment protection and sustainable development. Furthermore, the current study reinforces the dedication of Indian citizens to pull bull by the horns by ensuring that their small steps toward environmental protection result in significant changes toward the development of a more sustainable lifestyle.

KEY WORDS: ENVIRONMENT PROTECTION, CITIZEN, OPINION, PRACTICES, ROLES AND RESPONSIBILITY.

\section{INTRODUCTION}

Our planet Earth is currently dealing with several environmental issues. Global warming, acid rain, air pollution, urban sprawl, waste disposal, ozone layer depletion, water pollution, climate change, and other environmental issues affect every human, animal, and nation on the planet (Rinikesh 2020). These environmental problems decline in environmental quality results the loss of vegetation, biological diversity, excessive amounts of harmful chemicals in the ambient atmosphere and in food

Biosc Biotech Res Comm P-ISSN: 0974-6455 E-ISSN: 2321-4007

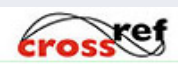

Identifiers and Pagination

Year: 2021 Vol: 14 No (9) Special Issue

Pages: 164-169

This is an open access article under Creative

Commons License Attribn 4.0 Intl (CC-BY).

DOI: http://dx.doi.org/10.21786/bbrc/14.9.31 grains, and rising risks of environmental accidents and threats to life support systems (Rai, 2016).

Environmental issues are referred to as a negative effects of human activity on the Earth and its natural systems. Climate change is one of the major environmental issue which affects everyone, and the consequences are visible in temperature fluctuations and an increase in severe natural disasters. It contributes to larger issues such as rising sea levels and biodiversity loss in our food systems. Another source of concern is pollution and its impact on public health. According to research, black carbon makes dangerous bacteria more difficult to kill and more resistant to antibiotics. Furthermore, air pollution raises the risk of heart attacks, strokes, and even lung cancer. In the past 100 years, extinction has been 100 times increased due to human interference, while sometimes a natural process, according to the Millennium Ecosystem Assessment. Disruptions to biodiversity would be detrimental not only to the environment, but also to human well-being.

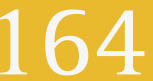


Through this food and energy security at risk, as well as access to safe water and materials, and it becomes more vulnerable to natural disasters. The vast amount of untested chemicals released into the environment and found in our foods and household items endangers public health (Giving Compass LLC, 2021).

In Atharvaveda, it has been said that "Man's paradise is on earth; this living world is the beloved place of all; It has the blessings of nature's bounties; live in a lovely spirit". Earth is our paradise and it is our duty to protect our paradise. The constitution of India embodies the framework of protection and preservation of nature without which life cannot be enjoyed. The knowledge of constitutional provisions regarding environment protection is need of the day to bring greater public participation, environmental awareness, and environmental education and sensitize the people to preserve ecology and environment (Vardhan, 2021). Government of India included amended in Article 51 for environmental protection and improvement as a constitutional mandate. Article $51 \mathrm{~A}(\mathrm{~g})$ particularly deals with fundamental duty with respect to the environment it says that "It shall be the duty of every citizen of India to protect and improve the natural environment including forests, lakes, rivers, and wildlife and to have compassion for living creatures (Hemant 2019; Kulin 2019).

The fundamental duty imposed on every citizen is not only to 'protect' the environment from any kind of pollution but also to improve the environment quality if it has been polluted so it is the duty of every citizen to preserve the environment in the same way as nature has gifted it to all of us (Hemant 2019). Environmental policies should be supported by the public to the extent that citizens believe it is the government's responsibility to protect the environment as a general principle. As a result, people should be more likely to support government spending on the environment if they believe that environmental protection is the government's primary responsibility (Kulin and Seva, 2019). The solutions to issues affecting sustainability should not be exclusively limited to corporate policies, strategies and standards (Lolatovic 2020; Paul 2018).

Although our individual actions seem insignificant, they can make a significant and positive contribution towards sustainability, our dedication and our awareness to genuinely sustainable development are essential. Individual efforts can make a significant contribution to achieving the goals of sustainable development. It must be understood that the challenges affecting sustainability are not limited to large businesses, we all contribute in some way to our grain of sand (Torneire, 2020). Lolatovic (2020) believed that even small things like, avoiding littering, taking care of our gardens, or balconies, planting trees and flowers would make our surroundings a more pleasant and beautiful place to spend time and have a positive impact on the environment.

Moreover, some governmental initiatives, and support towards creating conditions for waste recycling, prohibition of plastic bags, or making them more expensive, would be meaningful steps in that regard. As a social structure, there is a need recognize and comprehend the negative impact of our actions on the natural environment (Roy, 2019). Every person has a part to play in preserving the Earth's environment. A positive change, no matter how small, has the potential to create a long-lasting ripple of change (Paul, 2018). With this framework, through this study an attempt has been made to analyze the citizen's opinion and practices toward individual roles and responsibilities in environmental protection and to determine the factors behind the unhealthy behaviour of human towards environment and sustainable development (Alas 2021).

Statement of the Problem: Considering the problems related to health and environment, the purpose of the study was to assess opinion of citizen towards their individual roles and responsibilities for environmental protection and to evaluate the practices citizen's individual practices oriented toward environmental protection and sustainable development. To study the factors behind the unhealthy behaviour of human towards environment and sustainable development.

\section{Objectives:}

1. To assess citizen's opinion in order to determine individual roles and responsibility towards environmental protection.

2. To evaluate the citizen's individual practices oriented toward environmental protection and sustainable development.

3. To study the factors behind the unhealthy behaviour of human towards environment and sustainable development.

\section{MATERIAL AND METHODS}

The study was descriptive in nature. The primary and secondary data has been used to conduct the research. Random sampling has been used to collect data from 165 respondents. The tool used to collect data was Questionnaire method via Google form link. The questionnaire was divided into 4 section, the section 1 deals with the demographic profile of respondents included age, gender, education qualification, employment status and their income. Section 2 consisted various statement regarding the opinions of respondents on citizen's individual roles and responsibility towards the environment protection and environmental issues. Section 3 comprised of statements related to citizen's individual practices oriented toward environmental protection and sustainable development and the responses where the response structure was 'Never', 'Sometimes' and 'Most of the times'. Section 4 consisted the several factors i.e. unawareness, laziness, Damn care attitude of citizens, unnecessary use of resources etc. behind the unhealthy behaviour of human towards environment where the response structure was 'Strongly Disagree', 'Disagree', 'Neutral', 'Agree' and 'Strongly Agree' (Rinikesh 2021). 


\section{RESULTS AND DISCUSSION}

The results of the study obtained from the analysis of the data and their interpretations which are presented here (Torneire 2020).

i. Demographic profile of respondents: This section designated the demographic profile of respondents. This included age, gender, education qualification, employment status and their income. Data from figure 1 presents that less than three-fourth of the respondents $(73.80 \%)$ were in the age group of 19-35 years. More than one-half $(54.70 \%)$ of the respondents were male. Less than one-half $(45.60 \%)$ of the respondents had bachelor's degree. More than two-fifth (42.10\%) of the respondents were students. Nevertheless, less than two-fifth (39.30\%) of respondents had no income (Vardhan 2021).

Figure 1: Demographic profile of Respondents $(n=165)$

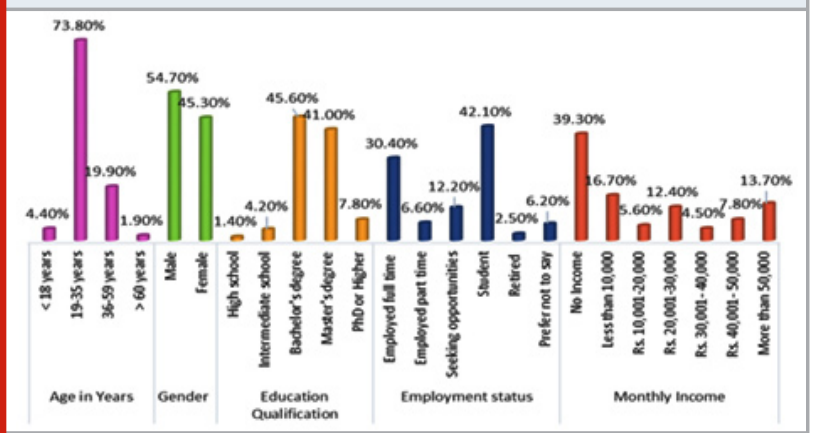

ii. Opinions of respondents towards environment protection and sustainable development: In this section probe was made to assess the opinion of the respondents that consisted different statement towards the environment protection and sustainable development.

a. Opinion on if 'we' (human) behind the environment degradation: this part deals with the opinion of respondents consider that there is 'we' (human) behind the degradation of environment where the response structure were "Extremely", "Moderately" and "Not at all”.

Figure 2: Opinion of citizens on 'we' (human) behind environment degradation $(n=165)$

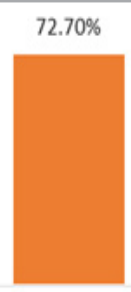

Extremely

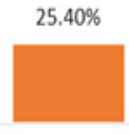

Moderately
$1.90 \%$

Not at all
Data from figure 2 which presents that less than threefourth of the respondents $(72.70 \%)$ were retorted that 'we' human were extremely behind the environment degradation followed by one-fourth $(25.40 \%)$ of respondents who considered that we humans are moderately behind the environment degradation. Moreover, only 1.90 per cent of the respondents did not believed that we humans behind environmental degradation (Tripathi 2003).

Figure 3: Opinion of citizens on individual's role and responsibility towards environment protection and sustainalbe development $(n=165)$

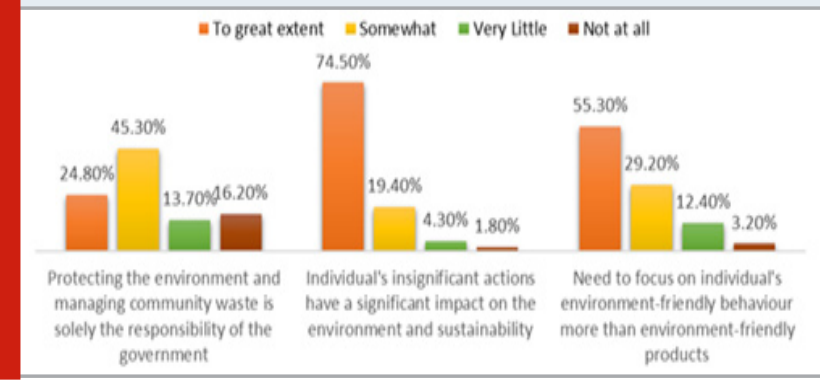

Figure 4: Opinion of citizenss on how changes can be made to protect the environment and sustainable development $(n=165)$

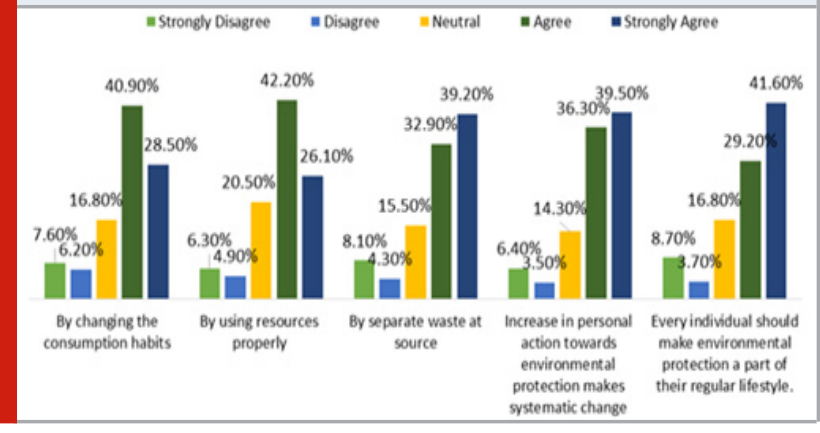

Figure 5: Citzen's Individual practices oriented towards environmental protection and sustainable development $(n=165)$

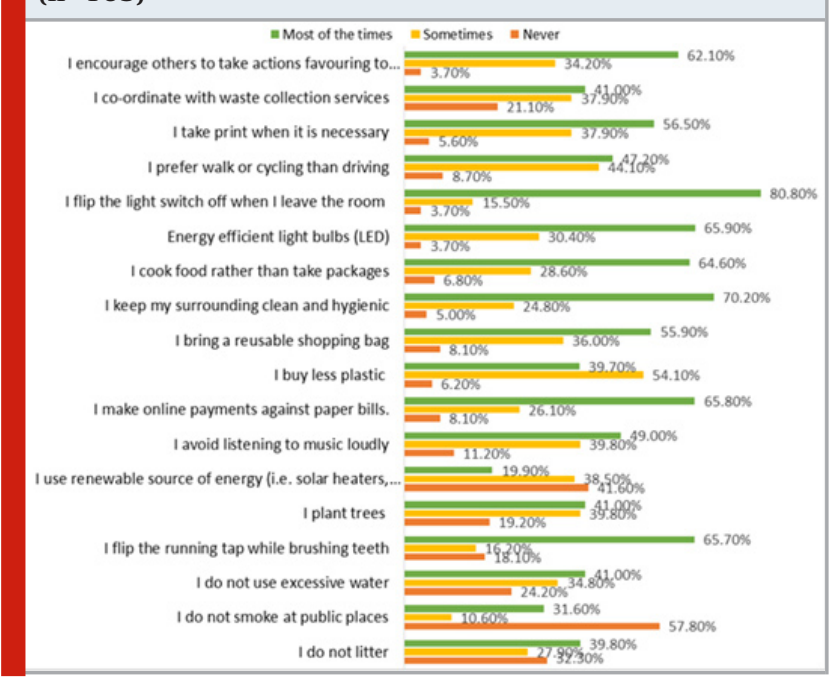

b. Opinion regarding individual's role and responsibility towards environment protection and sustainable development: this part deals with the opinions of 
respondents on individual role's and responsibility towards environment protection and sustainable development where the response structure was to "Great Extent", "Somewhat", "Very Little" and "Not at all".

Figure 3 shows that almost three-fourth (74.50\%) of the respondents were assumed that individual's insignificant actions have a significant impact on the environment and sustainable development at high extent. More than one-half (55.30\%) of the respondents supposed that need to focus on individual's environmentally-friendly behaviour is as important as to make environmentallyfriendly products at high extent. Furthermore, less than one-half $(45.30 \%)$ of the respondents somewhat implicit that protecting the environment is solely the responsibility of the government rather that individual responsibility of a citizen.

c. Opinion regarding how changes can be made to protect the environment and sustainable development: In this part, 'Likert' type scale encompassing 5 statements, which examined the respondents' opinions on the changes can be made to protect the environment and sustainable development where the responses were in the range of "Strongly Agree", "Agree", "Neutral", "Disagree" and "Strongly Disagree”.

Figure 6: Factors behind the unhealthy behaviour of citizens towards environment $(n=165)$

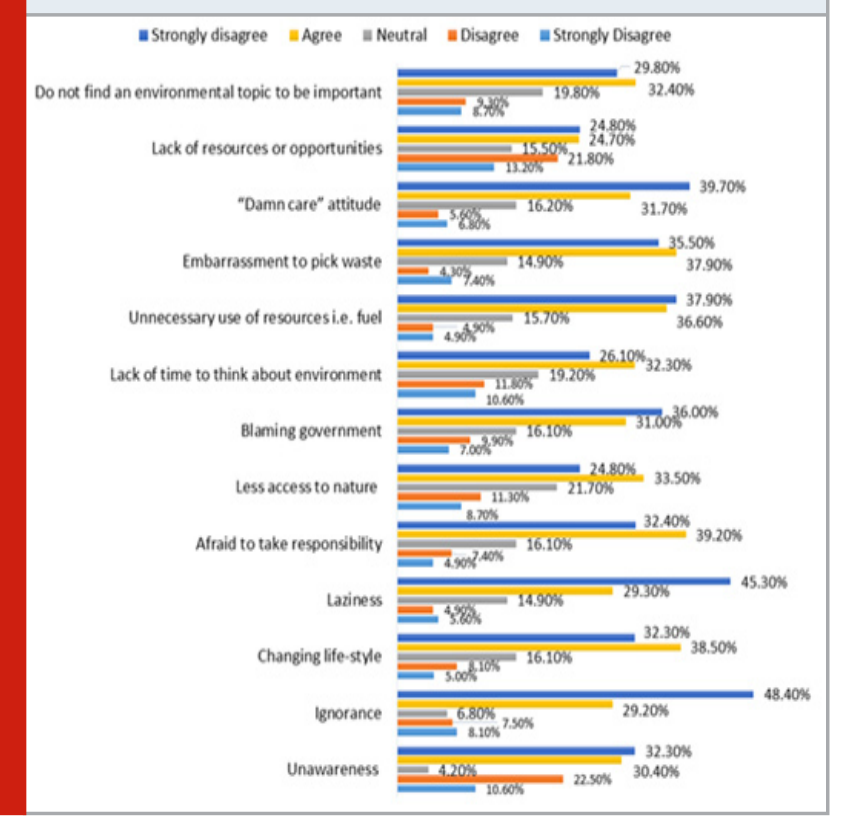

Lucid examination of data in figure 4 reveals that more than two-fifth (42.20\%) of the respondents were agreed that by using resources properly while using any products and trades an individual can protect the environment at their own level and helps to achieve sustainable development goals. More than two-fifth (41.60\%) of the respondents were strongly agreed that every individual should make environmental protection a part of their regular lifestyle which helps in to improve the environmental issues around the nation and sustainable development. Around two-fifth of the respondents (40.90\%) were agreed that changing the consumption habits, i.e. buying eco-friendly products, appropriate use of products helps to makes changes and protect environment at an individual level. Less than two-fifth $(39.50 \%)$ of the respondents were strongly agreed that changes can be made by increase in personal action towards environmental protection makes systematic change. Furthermore, less than one-fifth of respondents (39.20\%) were strongly agreed that waste separation at the source helps to avoid mixing of different waste (biodegradable and non-biodegradable) so that it can be used for other purposes and ensures good coordination with waste management services.

iii. Respondent's individual practices oriented toward environmental protection and sustainable development: In this section, an attempt was made to elicit respondents' individual practices toward environmental protection and sustainable development where the responses were "Never", "Sometimes" and "Most of the times".

Eloquent analysis of the data from figure 5 shows that around four-fifth of the respondents (80.80\%) reported that the flip the light switch off when they leave the rooms either in home or offices most of the times. More than two-third of the respondents (70. 20\%) keep their surrounding clean and hygienic most of the times. Less than two-third of the respondents were using energy efficient light bulbs (LED) (65.90\%), makes online payments against paper bills (65.80\%), flip the running tap while brushing teeth (65.70\%), cook food rather than take packages $(64.60 \%)$ and respondents (62.10\%) encourages others to take actions favoring to environment protection most of the times.

More than one-half of the respondents (54.10\%) sometimes buys less plastic to protect the environment. Less than one half of the respondents (44. 10\%) sometimes prefer walk or cycling rather than driving to avoid excessive use of fuel and save money to protect the environment and sustainability. More than one-third of the respondents sometimes plant trees (39.80\%), avoid listening to music loudly (39.80\%) to prevent noise pollution and occasionally using renewable source of energy (i.e. solar heaters, solar cookers) (38.50\%) to prevent the pollution in environment. Furthermore, more than one-half of the respondents (57.80\%) never smoke at public places to prevent air pollution and to make environment breathable for others. More than two-fifth of the respondents never used renewable source of energy (i.e. solar heaters, solar cookers) and less than one-fourth of the respondents $(21.10 \%)$ never co-ordinate with waste collection services.

iv. Factors behind the unhealthy behaviour of human towards environment: This section comprised the ultimate factors which contribute to the unhealthy behaviour of human towards the environment protection and sustainable development. To scrutinize the statements "Strongly Agree", "Agree”, "Neutral”, "Disagree” and "Strongly Disagree". 
Figure 6 elucidated that less than one-half of the respondents reported that ignorance $(48.40 \%)$ and laziness (45.30\%) among the citizens were the key factors behind the unhealthy behaviour of citizens towards environment protection and sustainable development. Less than two-fifth of the respondents reported that they strongly agreed with the factors like 'Damn care' attitude among citizens (39.70) were the one of the key factor affected unhealthy behavior of citizen towards environment. Less than two-fifth of the respondents reported agreed to the statements that citizen's afraid to take responsibilities (39.20\%), changing lifestyles $(38.50 \%)$ and embarrassment to pick waste (37.90\%) and unnecessarily and improper use of resources like fuel $(37.90 \%)$ by the citizen were the factors that contribute to unhealthy behavior that is harmful to the environment and a obstacles to achieve sustainable development goals.

Moreover, it was found that less than one-fourth of the respondent were disagreed that lack of awareness $(22.50 \%)$, lack of resources or opportunities $(21.80 \%)$ and lack of time to think about environment (11.80\%) were the key factors to contribute unhealthy behaviour towards the environment and the obstacle to achieve sustainable development goals.

\section{CONCLUSION}

The present revealed that respondents were in the age group of 19-35 years and were male had minimum qualification of bachelor's degree. Respondents described that 'we' human were extremely behind the environment degradation, and assumed that individual's insignificant actions have a significant impact on the environment and sustainable. Respondents were agreed that by using resources properly while using any products and trades an individual can protect the environment at their own level. The present study identified that respondents flip the light switch off when they leave the rooms either in home or offices most of the times. Respondents sometimes buys plastic to protect and sometimes used renewable source of energy to show concern towards the environment. Moreover the study revealed that ignorance and laziness among the citizens were the key factors behind the unhealthy behaviour of citizens towards environment protection and sustainable development. It can be concluded that through the present study that environment protection is not solely responsibility of government, everyone is equally responsible for creating and destroying the environment and therefore sustainability must be guaranteed for individual actions and small environmental choices to safeguard the environment.

The present study encourages the change in citizen's pattern of actions and healthy attitude which helps to protect the environment and sustainable development of the nation. According to the report by Alas (2021) US news, top 10 countries like New Zealand, Norway, Sweden, finland, Denmark, Switzerland, Canada, Netherlands Australia and Austria seen as caring the most for environment. It was evaluated by the strength of countries' "environmental protection laws" or "citizens attitudes and "actions" toward environment conservation. Like these countries, there is a need to understand our fundamental rights and fundamental duties towards environmental protection so that every citizen awake and helps in sustainable development. Furthermore, the current study reinforces the dedication of Indian citizens to pull bull by the horns by ensuring that their small steps toward environmental protection result in significant changes toward the development of a more sustainable lifestyle. The challenge is immense and to succeed, everyone should realize that while small actions may appear insignificant, they are actually critical.

\section{REFERENCES}

Alas,H. (2021). US News : These Countries Are Seen as Caring Most About the Environment. Retrieved on July 7, 2021 from https://www.usnews.com/news/bestcountries/slideshows/the-countries-that-care-mostabout-the-environment

Giving Compass LLC, (2021). Environmental Issues Guide: What To Know Now retrived on July 7, 2021 from https://givingcompass.org/article/environmentalissues/

Hemant (2019). Fundamental duties and Environment Protection. Retrieved on 30 june,2021 from https:// thefactfactor.com/facts/law/civil_law/environmental_ laws/duties-of-citizen-towards-environmentalprotection/1672/

Kulin, J., \&t Johansson Sevä, I. (2019). The Role of Government in Protecting the Environment: Quality of Government and the Translation of Normative Views about Government Responsibility into Spending Preferences. International Journal of Sociology, 49(2), 110-129. doi:10.1080/00207659.2019.1582964

Lolatovic, B. (2020). The importance of Individual contribution towards environment protection!. Retrieved on July 02, 2021 from https://www.thebf.org/ en/the-importance-of-individual-contribution-towardsenvironment-protection-

Paul, A. (2018). Role of an individual being to save the Green Earth. Retrieved on 4 July, 2021 from https:// moderndiplomacy.eu/2018/03/03/role-individual-savegreen-earth/

Rai, P.K. (2016) Particulate Matter and Its Size Fractionation. Book: Biomagnetic Monitoring of Particulate Matter. 1-3

Rinikesh (2021). What are environmental concerns. Conserve Energy Future. Retrieved on 7 july, 2021 form https://www.conserve-energy-future.com/top-25environmental-concerns.php

Roy, R.S. (2019). Role of Individual and sustainable development. Legal Services India. Retrieved on July 3, 2021 from http://www.legalservicesindia. 
com/article/452/Role-of-Individual-Et-SustainableDevelopment.html

Torneire, M. (2020). The role of individual advancing the Sustainable Development Goals. Developing Our World: Newsroom. Retrieved on July 7, 2021 from https://www. developingourworld.org/news-events/newsroom.html/ article/2020/03/31/the-role-of-individual-advancingthe-sustainable-development-goals
Tripathi, Y.C. and Tripathi, G. (2003). Some important environmental problems in India and their remedies. Book: Dimensions of Environmental Threats (Ed. Arvind Kumar), Chapter-49,376-382

Vardhan, P.P. (2021). Environment Protection under Constitutional Framework of India. ENVIS Centre, Ministry of Environment \& Forest, Govt. of India. Retrieved on July 4, 2021 from http://www.frienvis.nic.in/ ViewGeneralLatestNews.aspx?format=PrintEIId=981 